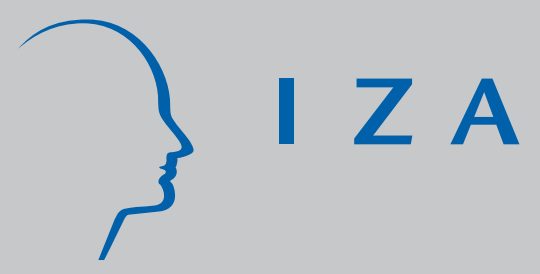

IZADP No. 2753

Physical Dating Violence Among College Students in Chile

J ocelyn A. Lehrer

Vivian L. Lehrer

Evelyn L. Lehrer

Zhenxiang Zhao

April 2007 


\title{
Physical Dating Violence Among College Students in Chile
}

\author{
Jocelyn A. Lehrer \\ University of California, San Francisco
}

Vivian L. Lehrer

Urban Justice Center

Evelyn L. Lehrer

University of Illinois at Chicago and IZA

Zhenxiang Zhao

University of Illinois at Chicago

Discussion Paper No. 2753

April 2007

IZA

P.O. Box 7240

53072 Bonn

Germany

Phone: +49-228-3894-0

Fax: +49-228-3894-180

E-mail: iza@iza.org

Any opinions expressed here are those of the author(s) and not those of the institute. Research disseminated by IZA may include views on policy, but the institute itself takes no institutional policy positions.

The Institute for the Study of Labor (IZA) in Bonn is a local and virtual international research center and a place of communication between science, politics and business. IZA is an independent nonprofit company supported by Deutsche Post World Net. The center is associated with the University of Bonn and offers a stimulating research environment through its research networks, research support, and visitors and doctoral programs. IZA engages in (i) original and internationally competitive research in all fields of labor economics, (ii) development of policy concepts, and (iii) dissemination of research results and concepts to the interested public.

IZA Discussion Papers often represent preliminary work and are circulated to encourage discussion. Citation of such a paper should account for its provisional character. A revised version may be available directly from the author. 


\section{ABSTRACT}

\section{Physical Dating Violence Among College Students in Chile*}

Dating violence is a serious public health concern both per se and because victimization in the young adult years can be a precursor to more severe incidents of domestic violence later, in the context of cohabitation or marriage. To date, no quantitative studies have examined dating violence among college students in Chile. To address this gap, a survey on this topic was administered to students at a major public university. The present analyses focused on the female sample $(n=441)$. Generalized ordered logit models were used to assess factors associated with physical victimization since age 14, considering three categories: no victimization, victimization with no injury, and victimization with injury. Approximately $21 \%$ of subjects reported one or more incidents of physical dating violence not involving injury since age 14 , and another $5.0 \%$ reported at least one incident resulting in injury during this time period. The corresponding figures for the past 12 months were $12.9 \%$ and $2.4 \%$, respectively. Childhood sexual abuse and witnessing domestic violence as a child were associated with substantially elevated odds of physical victimization later in life. Low parental education was also associated with higher vulnerability, in part because of its linkage with childhood experiences with aggression. Protective factors included maternal employment and religious service participation at age 14, residence in the parental home during the college years, and never having had sexual intercourse. The findings suggest that it would be desirable to develop public health initiatives to prevent and respond to this form of violence among Chilean college students.

JEL Classification: J4, J16, I12, I18

Keywords: domestic violence, dating violence, physical victimization

Corresponding author:

Evelyn L. Lehrer

University of Illinois at Chicago

Economics Department (m/c 144)

601 South Morgan Street

Chicago, IL 60607-7121

USA

Email: elehrer@uic.edu

\footnotetext{
* Partial support for this study was provided by the Center for Latin American Studies at Columbia University. Special thanks are due to Vaughn Rickert, Psy.D., for valuable suggestions regarding survey development and study design, and Houston Stokes, Ph.D. for helpful comments on an earlier draft of this paper. We also benefited from discussions with Pamela Oyarzun, M.D., and participants in seminars presented at the University of Chile's Center for Reproductive Medicine and Department of Social Sciences, August 2006.
} 


\section{INTRODUCTION}

As is true throughout Latin-America, Chilean society is afflicted by a high level of domestic violence, primarily directed at women and children (Larrain 1994; Morrison \& Biehl 1999; Urzua et al. 2002; Hassan et al. 2004); the socioeconomic, legal, and political factors that provide fertile ground for such violence have received considerable attention (McWhirter 1999; Bacigalupe 2000; Ceballo et al. 2004). The costs to the victims and broader society are far reaching, including mental and physical health costs, and various costs related to labor market performance, such as increased absenteeism, reduced productivity and earnings, and job loss (Morrison \& Biehl 1999; Lloyd \& Taluc 1999; Tiefenthaler \& Farmer 2000; Rickert et al. 2002; Rickert et al. 2003).

Research conducted in the U.S. in the 1980s and 1990s showed that intimate partner violence often begins in adolescence and young adulthood, and that levels of violence at these early ages are surprisingly high (Makepeace 1981; White \& Koss 1991; see also literature review by Lewis \& Fremouw 2001). Other studies also found high levels of sexual assault in college populations (Koss et al. 1987; Koss \& Dinero 1989; Rozee \& Koss 2001). In response to these research findings, many educational institutions in the U.S. currently have programs in place to prevent and respond to physical and sexual aggression.

To date, there have been no published quantitative studies of dating violence and sexual assault among Chilean college students, and campuses across the country lack systematized programs to address this public health concern. Designed to begin to address this gap in knowledge, a closed-ended questionnaire, the 2005 Survey of Student Well-Being, was administered to male and female students enrolled at a major public 
university in Santiago. The survey included questions regarding physical, psychological and sexual victimization, socioeconomic and demographic variables, and sexual abuse and witnessing of domestic violence in childhood.

The present paper focuses on women's physical dating violence victimization. It presents a descriptive analysis of its prevalence and the factors that are associated with it. Two main domains of subjects' lives were considered: socioeconomic and demographic characteristics, and childhood experiences with violence. The analysis was guided by an extensive U.S. literature on factors linked with youths’ vulnerability to dating violence victimization, with the goal of informing prevention strategies (Lewis \& Fremouw 2001, Vezina \& Hebert 2007).

\section{METHODS}

\section{Survey Development and Study Design}

The survey was compiled in English by the lead author and translated to Spanish by the third author, a Chilean native. Back-translation to English was conducted to ensure accuracy. The survey included scales that have been validated and widely used in the U.S. and other countries; some scale items were adapted to the Chilean social context and revised further based on comments from faculty members and students at the university. The second author conducted the field work after approval for the study was granted by the university's Ethics Committee for Research on Human Subjects.

One of the largest in the country, the university is a selective public institution with a socio-economically diverse student body. University officials provided access to the 25 General Education courses offered in Winter 2005; each of these classes was 
surveyed except one that had a session cancellation. The sample thus obtained included students enrolled in each of the educational programs of the university. Total enrollment in the General Education classes was 2,451, with some students registered in more than one course. At the time of survey administration, 1,193 students were present in the 24 classes combined; 970 students returned completed surveys, yielding an 81\% overall response rate. Students were instructed not to respond to the survey again if they had already completed it in another class; this accounts for some of the non-response.

At the beginning of the class period, the survey administrator discussed the nature and relevance of the survey, emphasizing that responses would be anonymous. Students provided written consent prior to completing the questionnaire, and deposited their completed, unsigned surveys in a box at the front of the room. The professor was absent during survey administration.

\section{Sample}

The final survey item asked subjects about the honesty of the responses they had provided. Two students reported giving non-honest responses and these cases were dropped, as well as two cases in which responses indicated that the survey had not been taken seriously; 16 cases with missing data on the student's sex were also dropped. The resultant base sample consisted of 484 women and 466 men.

This study utilized the female sample. Subjects were included in these analyses if they had ever had a date or dating relationship since age 14; 36 subjects who did not meet this criterion were dropped. Seven additional cases with missing data on physical dating violence outcomes were dropped, yielding a final sample of 441 subjects. 


\section{Measures}

\section{Dependent Variable}

Physical Victimization Survey items on physical dating violence were adapted from a scale used by Foshee (1996); items regarding injury were drawn from the Revised Conflict Tactics Scales (Straus et al. 2003) (Figure 1). Receipt of physical violence was operationalized as a trichotomous variable; the mutually exclusive categories indicate that the subject reported (a) no incident of physical violence; (b) at least one incident of physical violence but no injury; and (c) at least one incident resulting in injury. The survey instructed respondents to exclude incidents in which their partner was acting in self-defense (Lewis \& Fremouw 2001).

\section{Covariates}

Childhood sexual abuse $=1$ if the subject responded affirmatively to at least one of the following items: “Before age 14, did someone ever make you have sex against your will?” and "Before age 14, did you ever have any other form of unwanted sexual experience, such as forced kisses, grabbing, etc.?" Survey instructions indicated that “sex” refers to vaginal, oral or anal sex. Several studies have found an association between sexual or physical abuse during childhood and subsequent dating violence victimization (Coffey et al. 1996; O'Keefe 1998; Lehrer et al. 2006).

Witnessed domestic violence $=1$ if, before age 14 , the subject had ever witnessed violence between her parents or other adults who raised her. A meta-analysis of the relationship between witnessing domestic violence and subsequent victimization by a 
spouse found small to moderate effect sizes (Stith et al. 2000); a similar finding emerged from a recent analysis of dating violence victimization outcomes (Arriaga \& Foshee 2004).

Low parental education $=1$ if the highest level of parental education was twelve years of regular schooling or less, or incomplete advanced technical schooling or less. While study findings have been mixed, several studies in the U.S. and Latin America suggest that youth raised in socioeconomically disadvantaged homes are more likely to witness intrafamilial aggression (Kantor \& Jasinski 1998; Gonzalez de Olarte \& Orlando 1999; Urzua et al. 2002). There is also evidence linking low SES with a higher likelihood of childhood sexual abuse, although this may partly reflect the greater ease of detecting abuse in poorer households (Finkelhor 1994a). Low SES may be therefore indirectly associated with risk of subsequent victimization through its linkage with childhood experiences with aggression.

No attendance to religious services $=1$ if the subject reported no attendance to religious services at age 14. Some involvement with religious activities has been linked with beneficial effects for youth in a range of health domains, including less dating violence victimization (Howard et al. 2003; Gover 2004).

Residence with parents $=1$ if the subject had primarily resided in the parental home since enrolling in the university. This variable was expected to be associated with reduced exposure to victimization, because of greater opportunity for supervision and support.

Ever had sexual intercourse $=1$ if the subject reported having ever had voluntary vaginal or anal sex. Having had intercourse with the partner has been found to be 
associated with substantially elevated odds of physical abuse among adolescents (Kaestle \& Halpern 2005); along similar lines, research on college students has found violence to be more prevalent in long-term relationships (which are more likely to involve sexual intercourse) (Luthra \& Gidycz 2006).

\section{Control Variables}

Big city $=1$ if the subject resided in Santiago or another large urban area at age 14. Dating violence studies with high school samples have reported conflicting results regarding urbanicity: one analysis found urban residence to be associated with a higher risk of physical violence victimization as compared with rural residence (Bergman 1995); more recent work has reported the opposite (Spencer et al. 2000).

Maternal employment $=1$ the subject's mother worked outside the home when the subject was 14. Maternal employment has been linked with both positive and negative developmental outcomes for youth, including behavioral difficulties (Zaslow et al. 2003); it has also been found to be associated with daughters' less traditional gender role attitudes (Jan \& Janssens 1998). This factor may thus be indirectly associated with victimization risk.

Age $\geq \mathbf{2 1}=1$ if the subject was 21 years of age or older at the time of survey administration. This variable controls for length of exposure to victimization risk.

\section{Statistical Analysis}

Means for the independent variables and cross-tabulations were generated first, followed by descriptive statistics on physical victimization prevalence and characteristics 
of the most severe incident reported per subject. Generalized ordered logit models were then estimated to examine factors associated with victimization since age 14, using GOLOGIT2 in STATA version 9.2 (Williams 2006). This procedure utilizes information regarding the order of the three categories (i.e., the greater severity of an incident involving injury versus one not involving injury) and allows the proportional odds assumption to be relaxed for variables that fail to meet it. Sequential models were built: the control and family background variables were included first, followed by the living arrangements and sexual experience variables. The childhood violence variables were added last. Preliminary regressions included a nonintact family variable; it was insignificant in all models and therefore dropped. Predicted probabilities were calculated using the same computer program.

\section{RESULTS}

\section{Sample Descriptive Statistics}

Table 1 presents means for the independent variables. Although the subjects ranged from 18 to 30 years of age, 37.4\% were aged 21 years or older, reflecting students' tendency to take General Education courses early in their studies. Low SES, measured by parental education, characterized $30.2 \%$ of the sample.

Chilean youth typically live in the parental home during the college years; exceptions tend to be students raised in other parts of the country or whose families are wealthy. Consistent with this, $78.5 \%$ of the subjects had primarily resided with their parents since enrolling in the university. Fewer than $2 \%$ indicated primary residence with a partner or spouse. Students who lived away from their parents were disproportionately 
raised in nonmetropolitan areas $\left(\chi^{2}\right.$ test, $\left.\mathrm{P}<0.01\right)$ and in higher SES homes $(\mathrm{P}=0.05)$.

Religiosity and sexual debut were correlated: those who reported no religious services attendance were more likely to have initiated sexual activity $(\mathrm{P}<0.01)$.

Approximately 36\% of subjects reported having ever witnessed domestic violence before age 14. Over one-fifth of subjects reported childhood sexual abuse, within the 7\%36\% prevalence found for countries around the world (Finkelhor 1994a, 1994b). Subjects who reported witnessing domestic violence also more commonly reported sexual abuse, by a margin of 9.1 percentage points $(\mathrm{P}<0.01)$. Witnessing domestic violence and experiencing childhood sexual abuse were each more common, by margins of 17.0 and 11.0 percentage points, respectively, when parental education was low $(\mathrm{P}<0.01$ in each case).

\section{Prevalence of Physical Victimization and Characteristics of Most Severe Incident}

Over $20 \%$ of subjects reported one or more incidents since age 14 of physical victimization not involving injury, and another 5.0\% reported at least one incident resulting in injury during this period (Table 2). The corresponding twelve-month estimates were $12.9 \%$ and $2.4 \%$, respectively. More than one incident was reported by $44.3 \%$ of subjects who had ever been victimized since age 14 , and by $72.7 \%$ of those who reported receiving an injury during this period.

Although the response rate to survey items was generally very high, items that asked about the characteristics of the most severe incident of physical victimization were left unanswered by approximately half of the subjects who reported victimization. These items may have been particularly sensitive to some respondents; others may have felt that 
they had not experienced any severe incident. Among those who responded, the perpetrator was identified as a spouse and steady dating partner in $1.7 \%$ and $78.9 \%$ of the cases, respectively; more casual relationships were involved in the rest of the cases. In response to a question regarding whom, if anyone, the victim notified, no one reported contacting the police. Among the two-thirds of respondents who told someone, most told a friend (85\%) and/or their mother/ stepmother (30\%); 7.5\% told a doctor, psychologist or social worker.

\section{Generalized Ordered Logit Analyses}

The generalized ordered logit estimates are presented in Table 3. Brant tests in preliminary runs indicated that age and maternal employment violated the proportional odds assumption in all models; the corresponding odds ratios were therefore allowed to vary across categories. As indicated by the Wald tests, there were no violations of this assumption in the final models.

Model 1 indicates that for students aged 21 years and over, the odds of being in category 3 (victimization with injury) as opposed to categories 1 and 2 was 4.87 times the odds for their younger counterparts. Maternal employment had a large protective effect regarding victimization with injury (AOR 0.28). Subjects reporting no attendance to religious services at age 14 had 1.62 times the odds of reporting victimization $(\mathrm{P}=0.05)$, as compared to those who reported some service attendance.

Model 2 shows that living in the parental home was associated with lower odds of victimization (AOR 0.48) and that initiation of sexual activity was associated with increased odds (AOR 1.81). When these two variables were added to the model, the 
estimates for parental education, urbanicity and religosity changed substantially, reflecting the associations described earlier. The effects of low parental education and having been raised in a large urban area increased in magnitude and became significant (AOR 1.67 and 2.26, respectively). Model 1 may have concealed that growing up in a large city and a low-SES household were associated with higher odds of victimization partly because youth with these characteristics also disproportionately lived with their parents, which had a large protective influence. The loss of significance of religiosity in Model 2 suggests that youth who grow up with no religious service attendance may be more vulnerable to victimization partly because of their tendency to initiate sexual intercourse earlier.

Childhood sexual abuse and witnessing domestic violence were associated with elevated odds of victimization in Models 3 and 4 (AOR 1.95, P=0.01; AOR 1.58, $\mathrm{P}=0.05$ ). As noted earlier, these variables were correlated; Model 5, which includes both, shows smaller effects. In addition, in going from Model 2 to Model 5, the effect of low parental education decreased in magnitude and lost significance, suggesting that childhood experiences with aggression mediate the effect of low SES in the family of origin.

Table 4 presents predicted probabilities of victimization, using Models 1 and 5 to illustrate the absolute magnitudes of the effects. For example, Model 5 shows that for a subject who did not report childhood sexual abuse and had typical characteristics for the other independent variables, the probability of reporting no incidents of victimization since age 14 was 0.83 ; for her counterpart who reported childhood sexual abuse, the probability was 11 percentage points lower. 


\section{DISCUSSION}

In the U.S., Makepeace’s (1981) investigation of dating violence among college students found that approximately one-fifth of the students surveyed reported physical dating violence victimization. This initial finding led to numerous subsequent efforts to estimate prevalence rates in U.S. youth populations, identify risk factors, and develop and evaluate prevention programs (White \& Koss 1991; Lewis \& Fremouw 2001). In the present Chilean sample, 25.6\% of female subjects reported physical dating violence victimization since age 14 years and $15.3 \%$ reported victimization in the past 12 months, suggesting that dating violence among Chilean college students is similarly an issue warranting further public health attention.

Dating violence prevention strategies in the U.S. have typically included efforts to alter youths’ attitudes and beliefs regarding the legitimacy of violence in interpersonal relations (Foshee et al. 1996; Avery-Leaf et al. 1997; MacGowan 1997). Such initiatives seem particularly pressing in the context of Chile’s conservative society, where permissive attitudes toward family violence and beliefs that men may demonstrate their love through violent behavior are widespread (McWhirter 1999; Ceballo et al. 2004). The legal landscape in Chile has both reflected and reinforced such attitudes; for example, divorce was legalized in 2004 (making Chile the last Western country to do so), and the first law regarding sexual harassment in the workplace was passed in 2005.

In this study, low SES was linked with higher odds of dating violence victimization. Further analyses indicated that witnessing domestic violence and experiencing childhood sexual abuse were associated with higher victimization risk, and 
that the linkage between low SES and increased vulnerability was indirect - through the higher prevalence of these forms of aggression in socio-economically disadvantaged households.

Being raised with some participation in religious activities had a protective effect. Additional analyses suggested that the beneficial effect of such participation may stem partly from its influence on delaying sexual debut. Religiosity is associated with other positive health outcomes for youth, including less substance use (Koenig et al. 2001; Gover 2004); such factors may have played a role here as well.

Students who live away from their parents were found to be more vulnerable to dating violence victimization, meriting particular attention in Chilean prevention programs. Consistent with findings from previous studies (Kaestle \& Halpern 2005; Luthra \& Gidycz 2006), subjects who had initiated sexual activity were also found to have higher odds of victimization, reflecting in part the association of sexual intercourse with more emotionally intense or committed relationships where violence is more likely. At the same time, subjects who choose to live away from home and/or to become sexually active probably have unobserved characteristics that augment vulnerability-- the present estimates are thus likely to overstate the effects associated with these variables.

Maternal employment during the subject's childhood had a substantial protective effect against incidents of violence involving injury. Future research should examine the extent to which young women raised by working mothers develop attitudes and/or skills that decrease vulnerability.

At the methodological level, this study makes three main contributions to the dating violence literature. First, although causality cannot be inferred from these cross- 
sectional analyses, the age-specific variables and sequential models suggest potential mechanisms linking factors to victimization risk which merit further investigation. Second, the varying magnitude and significance of effects across models sheds some light on discrepancies among results reported in the literature, as previous studies differ on the sets of variables examined. Third, this study is among the first in the field to employ the generalized ordered logit technique, utilizing information on the distinction between violence that results in injury versus less severe forms, and allowing for the possibility of non-proportional odds. Some of the relationships described here (e.g., the effects of age and maternal employment) were statistically insignificant in preliminary logistic regressions with a dependent variable that only distinguished between some victimization versus none, the methodology generally used in previous research.

The study has various limitations. Although the sample included a wide range of students enrolled in the university, the study findings cannot be generalized to the entire student body. The victimization prevalence findings are likely to be understimates, since partner violence is commonly underreported due to factors including denial, not interpreting aggression as such, social desirability bias and recall error (Koss et al. 1994; Lewis \& Fremouw 2001). In addition, a substantial proportion of eligible subjects were absent on the day of survey administration, most likely including a disproportionate number of higher-risk individuals.

In summary, this study represents an initial step in the process of gathering evidence on the prevalence of and risk factors for physical dating violence victimization among female college students in Chile. The findings indicate that it would be beneficial to collect additional data on both victimization and perpetration, and to begin to develop 
theory-based public health initiatives to prevent and respond to this form of violence among Chilean youth. The study findings also suggest that it may be beneficial to initiate similar investigations in other Latin American countries where data in this area have yet to be collected and campus programs have yet to be developed. 


\section{REFERENCES}

Almeras D, Bravo R, Milosavljevic, Montano S, et al. Intimate Partner Violence Against Women: Latin America and the Caribbean. (In Spanish) CEPAL, United Nations, 2002. Available at: http://www.isis.cl/temas/vi/doc2.htm . Accessed November 30, 2006.

Arriaga XB and Foshee VA. Adolescent dating violence: Do adolescents follow in their friends', or their parents', footsteps? J Interpers Violence 2004;19:162-184.

Avery-Leaf S, Cascardi M, O'Leary KD, et al. Efficacy of a dating violence prevention program on attitudes justifying aggression. J Adolesc Health 1997;21:11-17.

Bacigalupe G. Family violence in Chile: Political and legal dimensions in a period of demographic transition. Violence Against Women 2000;6:427-448.

Bandura A. Social Learning Theory. New York: General Learning Press; 1977.

Bergman L. Dating violence among high school students. Social Work 1992;37:21-27.

Ceballo R, Ramirez C, Castillo M, et al. Domestic violence and women's mental health in Chile. Psychol Women Q 2004;28:298-308.

Coffey P, Leitenberg H, Henning K, et al. Dating violence: The association between methods of coping and women's psychological adjustment. Violen Vic 1996;11:227-238.

Finkelhor D. Current information on the scope and nature of child sexual abuse. Future Child 1994a;4:31-53.

Finkelhor D. The international epidemiology of child sexual abuse. Child Abuse Negl 1994b;18:409-417. 
Foshee VA. Gender differences in adolescent dating abuse prevalence, types and injuries. Health Educ Res 1996;11:275-286.

Foshee VA, Linder GF, Bauman KE, et al. The Safe Dates Project: Theoretical basis, evaluation design, and selected baseline findings. Am J Prev Med 1996; 12(Suppl):39-47.

Gonzalez de Olarte E, Gavilano Llosa P. Does poverty cause domestic violence? Some answers from Lima. In Morrison AR \& Loreto Biehl M, eds. Too Close to Home: Domestic Violence in the Americas. Washington DC: Inter-American Development Bank,1999:35-50.

Gover AR. Risky lifestyles and dating violence: A theoretical test of violent victimization. J Crim Justice 2004;32:171-180.

Hassan F, Sadowski LS, Bangdiwala SI, et al. Physical intimate partner violence in Chile, Egypt, India and the Philippines. Inj Control Saf Promot 2004;11:111-116.

Howard D, Qiu Y, Boekeloo B. Personal and social contextual correlates of adolescent dating violence. J Adolesc Health 2003;33:9-17.

Jan CT, Janssens MA. Maternal influences on daughters' gender role attitudes. Sex Roles 1998;38:171-186.

Kaestle CE, Halpern CT. Sexual intercourse precedes partner violence in adolescent romantic relationships. J Adolesc Health 2005;36:386-392.

Kantor GK, Jasinski JL. Dynamics and risk factors in partner violence. In Jasinski JL \& Williams LM, eds. Partner Violence: A Comprehensive Review of 20 Years of Research. London: Sage Publications, 1998:1-43. 
Koenig HG., McCullough ME, Larson DB. Handbook of Religion and Health. New York: Oxford University Press, 2001.

Koss MP, Dinero TE. Discriminant analysis of risk factors for sexual victimization among a national sample of college women. Journal of Consulting and Clinical Psychology. 1989;57(2):242-250.

Koss MP, Gidycz CA, Wisniewski N. The scope of rape: incidence and prevalence of sexual aggression and victimization in a national sample of higher education students. J Counsel Clin Psych. 1987;55(2):162-170.

Koss MP, Goodman LA, Browne A, et al. No Safe Heaven: Male Violence Against Women at Home, at Work and in the Community. Washington, DC: American Psychological Association, 1994.

Larrain SH. Violence Behind Doors: The Battered Woman [in Spanish]. Santiago, Chile: Editorial Universitaria, 1994.

Lehrer JA, Buka S, Gortmaker S, et al. Depressive symptomatology as a predictor of exposure to intimate partner violence among US female adolescents and young adults. Arch Pediatr Adolesc Med 2006;160:270-276.

Lewis SF, Fremouw W. Dating violence: a critical review of the literature. Clin Psychol Rev 2001;21:105-127.

Lloyd S, Taluc. The Effects of Male Violence on Female Employment. Violence Against Women199; 5(4):370-392.

Luthra R, Gidycz CA. Dating violence among college men and women. J Interpers Violence 2006;21:717-731. 
Macgowan, MJ. An evaluation of a dating violence prevention program for middle school students. Violence Vict 1997;12:223-235.

Makepeace JM. Courtship violence among college students. Fam Relat 1981;30:97-102.

McWhirter PT. La violencia privada: domestic violence in Chile. Am Psychol 1999; 54:37-40.

Morrison AR, Biehl ML. Too Close to Home: Domestic Violence in the Americas. Washington D.C.: Inter-American Development Bank, 1999.

O’Keefe M. Factors mediating the link between witnessing interparental violence and dating violence. J Fam Violence 1998;13:39-57.

Rickert VI, Vaughan RD, Wiemann CM. Adolescent dating violence and date rape. Current Opinion in Obstetrics and Gynecology 2002;14:495-500.

Rickert VI, Vaughan RD, Wiemann CM. Violence against young women: implications for clinicians. Contemporary OB/GYN 2003;2:30-45.

Spencer GA, Bryant SA. Dating violence: A comparison of rural, suburban, and urban teens. J Adolesc Health 2000;27:302-305.

Stith SM, Rosen KH, Middleton KA, et al. The intergenerational transmission of spouse abuse: A meta-analysis. J Marriage Fam 2000;62:640-654.

Straus MA, Hamby SL, Warren WL. The Conflict Tactics Scales Handbook: Revised Conflict Tactics Scale (CTS2); CTS: Parent-Child Version (CTSPC). Los Angeles, CA: Western Psychological Services. 2003.

Tiefenthaler J, Farmer A. The employment effects of domestic violence. Discussion Paper \#100-04, Economics Department, Colgate University, 2000. 
Urzua R, Ferrer M, Gutierrez C, et al. Detection and Analysis of the Prevalence of Intrafamily Violence [in Spanish]. Santiago, Chile, SERNAM, 2002.

Vezina J, Hebert M. Risk factors for victimization in romantic relationships of young women: A review of empirical studies and implications for prevention. Trauma Violence Abuse 2007;8:33-66.

White JW, Koss MP. Courtship violence: incidence in a national sample of higher education students. Violence Vict 1991;6:247-256.

Williams RA. Generalized ordered logit/ partial proportional odds models for ordinal dependent variables. The Stata Journal 2006;6:58-82.

Zaslow M, Jekielek S, Gallagher M. Match and Mismatch through a developmental lense: The implications of maternal employment for children of different ages. Paper presented at meeting on Workforce/Workplace Mismatch? Work, Family, Health and Well-Being, Washington DC, 2003. Available at: http://www.popcenter.umd.edu/conferences/nichd/papers/zaslow.pdf. Accessed December 7, 2006. 


\section{Figure 1. Survey Items Regarding Physical Violence and Injury}

(Past 12 Months and Since Age 14)

\section{Panel A: Incidents of Physical Violence}

How many times has any person with whom you have had a romantic relationship or gone out on a date done one of the things mentioned below? If it ever happened that your partner did something in self-defense, in response to something you initiated, exclude those cases.

(Never; 1-2 times; 3-5 times; 6 times or more)

Scratched or slapped me

Pushed, grabbed, or shoved me

Slammed me or held me against a wall

Kicked or bit me

Hit me with a fist

Hit me with something hard

Beat me repeatedly

Tried to choke me

Burned me

Assaulted me with a knife or gun

\section{Panel B: Physical Injury ${ }^{a}$}

Have any of the following things happened to you due to a fight with your partner or somebody with whom you have dated?

(Yes/ No)

I had a sprain, bruise or small cut because of a fight with a dating partner I passed out from being hit on the head by my dating partner in a fight I went to a doctor for an injury from a fight with my partner I needed to see a doctor for an injury from a fight with my partner, but didn’t go

a Based on the likelihood of resultant injuries, work by Foshee (1996) classified the first two items in Panel A as representing "mild violence," the second two as "moderate violence," and the remainder as "severe violence." Ancillary analyses in the present study showed that, consistent with Foshee's results, injuries were more common when severe violence was involved: the injury rate ranged from $23.7 \%$ to $24.5 \%$ in cases of mild or moderate violence; in instances of severe violence it ranged from $42.9 \%$ for students who were hit with a fist, to $100 \%$ for those who were burned or beat repeatedly. 
Table 1. Descriptive Statistics for Independent Variables ${ }^{\mathrm{a}}$

$(n=441)$

\section{Covariates}

Low parental education

$30.2 \%$

No attendance to religious services

24.0

Residence with parents

78.5

Ever had sexual intercourse

64.9

Experienced childhood sexual abuse

20.9

Witnessed domestic violence

36.3

Controls

Big City

77.6

Maternal employment

60.5

Age $\geq 21$

37.4

${ }^{\mathrm{a}}$ Estimates represent the percentage of cases in which the variable equals 1 .

Note: To minimize loss of information, cases with missing data for the independent variables were addressed by imputing the modal category; 11-13 cases were imputed for the childhood violence variables, and fewer than 8 for each of the other variables. The only exception was the sexual debut variable which had 29 observations with missing data. In preliminary analyses a missing dummy variable indicator was created and added to the multivariate models. It was insignificant in all models and dropped as none of the results were affected. 
Table 2. Percentage of Students Reporting Physical Violence Victimization

\begin{tabular}{lcc}
\hline & $\begin{array}{c}\text { Since Age } 14 \\
\mathrm{n}=441\end{array}$ & $\begin{array}{c}\text { Past } 12 \text { months } \\
\mathrm{n}=412^{\mathrm{a}}\end{array}$ \\
\hline Violence with physical injury & 5.0 & 2.4 \\
Violence with no physical injury & 20.6 & 12.9 \\
No incidents of dating violence & 74.4 & 84.7 \\
$\quad$ & $100 \%$ & $100 \%$ \\
\hline
\end{tabular}

a 29 observations with missing data on past 12-month victimization were dropped. 
Table 3. Generalized Ordered Logit Estimates: Physical Victimization ${ }^{\text {a }}$ Odds Ratios (P-value) [95\% confidence interval]

\begin{tabular}{|c|c|c|c|c|c|c|}
\hline \multirow{2}{*}{\multicolumn{2}{|c|}{ Bivariate analyses }} & \multicolumn{5}{|c|}{ Multivariate analyses } \\
\hline & & Model 1 & Model 2 & Model 3 & Model 4 & Model 5 \\
\hline $\begin{array}{l}\text { COVARIATES } \\
\text { Low parental } \\
\text { education }\end{array}$ & $\begin{array}{l}1.63(0.03)^{*} \\
{[1.04-2.54]}\end{array}$ & $\begin{array}{l}1.51(0.08) \\
{[0.95-2.38]}\end{array}$ & $\begin{array}{l}1.67(0.03){ }^{*} \\
{[1.05-2.67]}\end{array}$ & $\begin{array}{l}1.59(0.06) \\
{[0.99-2.54]}\end{array}$ & $\begin{array}{l}1.52(0.09) \\
{[0.94-2.44]}\end{array}$ & $\begin{array}{l}1.45(0.13) \\
{[0.90-2.35]}\end{array}$ \\
\hline $\begin{array}{l}\text { No attendance } \\
\text { to religious } \\
\text { services }\end{array}$ & $\begin{array}{l}1.58(0.06) \\
{[0.98-2.55]}\end{array}$ & $\begin{array}{l}1.62(0.05)^{*} \\
{[1.00-2.63]}\end{array}$ & $\begin{array}{l}1.46(0.13) \\
{[0.89-2.39]}\end{array}$ & $\begin{array}{l}1.46(0.14) \\
{[0.89-2.41]}\end{array}$ & $\begin{array}{l}1.46(0.14) \\
{[0.89-2.40]}\end{array}$ & $\begin{array}{l}1.47(0.13) \\
{[0.89-2.42]}\end{array}$ \\
\hline $\begin{array}{l}\text { Residence } \\
\text { with parents }\end{array}$ & $\begin{array}{l}0.79(0.37) \\
{[0.48-1.32]}\end{array}$ & -- & $\begin{array}{l}0.48(0.03)^{*} \\
{[0.24-0.93]}\end{array}$ & $\begin{array}{l}0.47(0.03)^{*} \\
{[0.24-0.93]}\end{array}$ & $\begin{array}{l}0.54(0.07) \\
{[0.27-1.06]}\end{array}$ & $\begin{array}{l}0.53(0.07) \\
{[0.27-1.04]}\end{array}$ \\
\hline $\begin{array}{l}\text { Ever had sexual } \\
\text { intercourse }\end{array}$ & $\begin{array}{l}1.88(0.01)^{* *} \\
{[1.17-3.02]}\end{array}$ & -- & $\begin{array}{l}1.81(0.02)^{*} \\
{[1.09-3.02]}\end{array}$ & $\begin{array}{l}1.76(0.03)^{*} \\
{[1.05-2.95]}\end{array}$ & $\begin{array}{l}1.75(0.03)^{*} \\
{[1.05-2.92]}\end{array}$ & $\begin{array}{l}1.70(0.04)^{*} \\
{[1.01-2.84]}\end{array}$ \\
\hline $\begin{array}{l}\text { Experienced } \\
\text { childhood } \\
\text { sexual abuse }\end{array}$ & $\begin{array}{c}2.10(<0.01)^{* *} \\
{[1.30-3.41]}\end{array}$ & -- & - & $\begin{array}{c}1.95(0.01)^{* *} \\
{[1.18-3.21]}\end{array}$ & - & $\begin{array}{c}1.89(0.01)^{* *} \\
{[1.14-3.12]}\end{array}$ \\
\hline $\begin{array}{l}\text { Witnessed } \\
\text { domestic } \\
\text { violence }\end{array}$ & $\begin{array}{c}1.80(0.01)^{* *} \\
{[1.17-2.77]}\end{array}$ & -- & -- & -- & $\begin{array}{l}1.58(0.05)^{*} \\
{[1.00-2.50]}\end{array}$ & $\begin{array}{l}1.52(0.08) \\
{[0.95-2.41]}\end{array}$ \\
\hline $\begin{array}{l}\text { CONTROLS } \\
\text { Big City }\end{array}$ & $\begin{array}{l}1.56(0.12) \\
{[0.90-2.70]}\end{array}$ & $\begin{array}{l}1.47(0.18) \\
{[0.84-2.56]}\end{array}$ & $\begin{array}{l}2.26(0.03)^{*} \\
{[1.10-4.63]}\end{array}$ & $\begin{array}{l}2.32(0.02)^{*} \\
{[1.14-4.73]}\end{array}$ & $\begin{array}{l}2.05(0.05)^{*} \\
{[1.00-4.21]}\end{array}$ & $\begin{array}{l}2.13(0.04)^{*} \\
{[1.04-4.37\}}\end{array}$ \\
\hline Maternal & & & & & & \\
\hline 1 vs $2 \& 3$ & $\begin{array}{l}0.73(0.15) \\
{[0.47-1.12]}\end{array}$ & $\begin{array}{l}0.75(0.21) \\
{[0.48-1.17]}\end{array}$ & $\begin{array}{l}0.71(0.14) \\
{[0.45-1.11]}\end{array}$ & $\begin{array}{l}0.72(0.16) \\
{[0.45-1.14]}\end{array}$ & $\begin{array}{l}0.66(0.08) \\
{[0.42-1.06]}\end{array}$ & $\begin{array}{l}0.68(0.11) \\
{[0.43-1.09]}\end{array}$ \\
\hline $1 \& 2$ vs 3 & $\begin{array}{c}0.29(0.01)^{* *} \\
{[0.11-0.72]}\end{array}$ & $\begin{array}{c}0.28(0.01)^{* *} \\
{[0.11-0.70]}\end{array}$ & $\begin{array}{c}0.27(0.01)^{* *} \\
{[0.11-0.67]}\end{array}$ & $\begin{array}{c}0.27(0.01)^{* *} \\
{[0.11-0.67]}\end{array}$ & $\begin{array}{c}0.25(<0.01)^{* *} \\
{[0.10-0.63]}\end{array}$ & $\begin{array}{c}0.25(<0.01)^{* *} \\
{[0.10-0.64]}\end{array}$ \\
\hline Age & & & & & & \\
\hline $\begin{array}{l}1 \text { vs } 2 \& 3 \\
1 \& 2 \text { vs } 3\end{array}$ & $\begin{array}{c}1.33(0.20) \\
{[0.86-2.06]^{* *}} \\
4.83(<0.01)^{* *} \\
{[1.85-12.61]}\end{array}$ & $\begin{array}{c}1.32(0.21) \\
{[0.85-2.06]^{* *}} \\
4.87(<0.01)^{* *} \\
{[1.88-12.65]}\end{array}$ & $\begin{array}{l}1.07(0.79) \\
{[0.67-1.70]} \\
3.89(0.01)^{* *} \\
{[1.48-10.25]}\end{array}$ & $\begin{array}{c}1.02(0.95) \\
{[0.63-1.63]} \\
3.76(0.01)^{* *} \\
{[1.42-9.92]}\end{array}$ & $\begin{array}{c}1.08(0.76) \\
{[0.67-1.72]} \\
3.97(0.01)^{* *} \\
{[1.51-10.49]}\end{array}$ & $\begin{array}{l}1.03(0.91) \\
{[0.64-1.65]} \\
3.86(0.01)^{* *} \\
{[1.46-10.23]}\end{array}$ \\
\hline $\begin{array}{l}\log L \\
\chi^{2} \\
\text { (P-value, df) }\end{array}$ & $\begin{array}{l}-- \\
--\end{array}$ & $\begin{array}{c}-291.79 \\
29.76^{* *} \\
(<0.01,7)\end{array}$ & $\begin{array}{c}-286.58 \\
40.17^{* *} \\
(<0.01,9)\end{array}$ & $\begin{array}{c}-283.29 \\
46.76^{* *} \\
(<0.01,10)\end{array}$ & $\begin{array}{c}-284.71 \\
43.91^{* *} \\
(<0.01,10)\end{array}$ & $\begin{array}{c}-281.75 \\
49.84^{* *} \\
(<0.01,11)\end{array}$ \\
\hline $\begin{array}{l}\text { Wald-test } \\
\text { (P-value, df) }\end{array}$ & -- & $\begin{array}{c}3.96 \\
(0.27,3)\end{array}$ & $\begin{array}{c}4.69 \\
(0.46,5)\end{array}$ & $\begin{array}{c}4.50 \\
(0.61,6)\end{array}$ & $\begin{array}{c}4.67 \\
(0.59,6)\end{array}$ & $\begin{array}{c}4.56 \\
(0.71,7)\end{array}$ \\
\hline
\end{tabular}

\footnotetext{
${ }^{\mathrm{a}}$ Dependent variable is trichotomous:

1 (no victimization); 2 (victimization with no injury); or 3 (victimization with injury)

${ }^{* *} \mathrm{p}<0.01 ;{ }^{*} \mathrm{p}<0.05$
} 
Table 4. Predicted Probabilities for Selected Values of Independent Variables

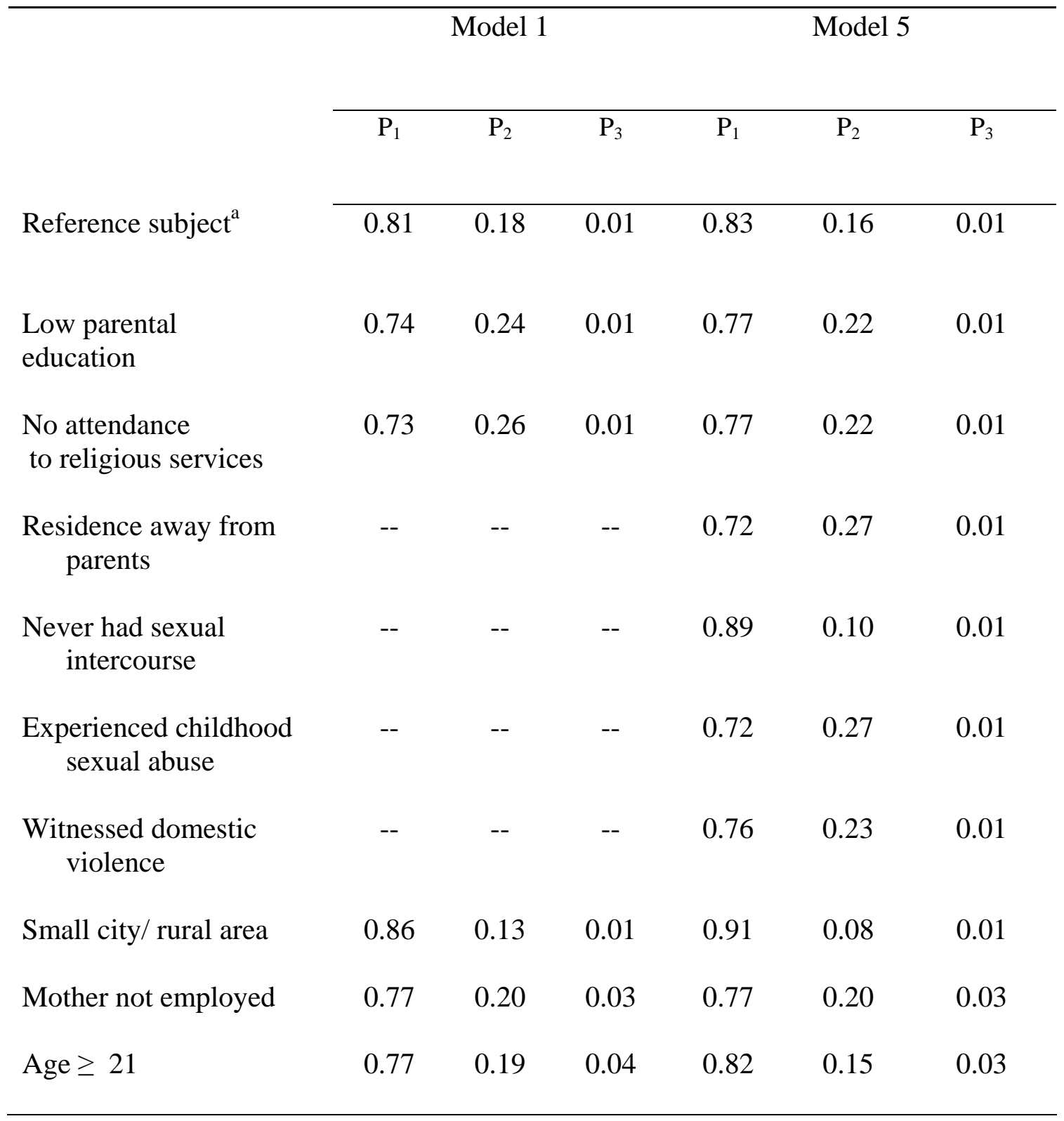

${ }^{a}$ The probabilities reported in this first row are for a "reference subject," a student who has the modal characteristics: high parental education; attendance to religious services at age 14; residence with parents since college enrollment; had initiated sexual activity; no report of childhood sexual abuse; never witnessed domestic violence; lived in big city at age 14; mother worked outside home at age 14; age under 21 . The probabilities reported in the other rows correspond to subjects who differ from the "reference subject" in only one trait, as noted in the stub.

Note: $\mathrm{P}_{1}, \mathrm{P}_{2}$, and $\mathrm{P}_{3}$ are the probabilities of no victimization, victimization with no injury, and victimization with injury, respectively. 